\title{
Revista EaD \\ tecnologias digitais na educação
}

\section{A utilização das TICs como material peda- gógico no ensino fundamental 1 , do colégio privado Losango de Ubá-MG: suportes e contribuições do código QR no auxílio à prática educacional}

\author{
Camilla Capryth, UNIFAGOC \\ capryth@gmail.com
}

\section{Ana Amélia de Souza Pereira, UNIFAGOC aamelia.mg@gmail.com}

Resumo: A revolução tecnológica vivenciada atualmente exige mudança no campo educacional, portanto fazer o uso da tecnologia nas escolas já é uma necessidade inadiável. As crianças desde cedo despertam o interesse pela te cnologia, visto que usar um tablet, smartphone ou computador é algo normal, que elas conseguem fazer sem grandes dificuldades. Este trabalho teve como objetivo analisar a utilização do código $Q R$ no Ensino Fundamental I das disciplinas básicas do Colégio Losango de Ubá-MG. Para a realização deste trabaIho, optou-se pela pesquisa de campo de natureza quali-quantitativa, com a utilização de uma entrevista e um questionário fechado. A análise de dados foi processada por meio do software Iramuteq e do programa Excel da Microsoft Office 365. Conclui-se que o código $Q R$ nos materiais didáticos funciona como ferramenta que auxilia com benefício na transmissão de conhecimentos, além de assegurar incontáveis possibilidades de aprendizagem, trazendo a tecnologia educacional para o universo da sala de aula.

Palavras-chave: Qrcode. Tics. Ensino Fundamental. Iramuteq. 


\section{Introdução}

Dentre as principais características da sociedade contemporânea, a tecnologia se encontra presente no cotidiano das pessoas. Com o surgimento de equipamentos eletrônicos como computadores e smartphones, ela permanece inserida no processo de trabalho, lazer, saúde, entre tantas outras áreas, inclusive na educação, proporcionando incontáveis benefícios, devido à rapidez ao acesso de informações.

De acordo com Fiorio et al. (2014), a adição de tecnologias como método pedagógico pode se mostrar propícia para aumentar o desejo por conhecimento e a evolução de outras aptidões necessárias ao aluno, com vistas a preparar os jovens para uma educação de qualidade, buscando formas de tornar as aulas mais divertidas e estimulantes.

A revolução tecnológica vivenciada exige uma mudança no campo educacional, portanto fazer o uso da tecnologia nas escolas já é uma necessidade inadiável. As cria nças desde cedo despertam o interesse pela tecnologia, visto que usar um tablet, smartphone ou computador é algo normal que elas conseguem fazer sem grandes dificuldades.

As tecnologias de informação e da comunicação (TICs) têm sido relevantes no cenário atual, tanto na contribuição e no benefício que as ferramentas podem assegurar, quanto no campo da educação, aliando-se às práticas de ensino e ao projeto pedagógico.

De acordo com Ponte (2002), as tecnologias de informação e da comunicação estabelecem um meio para aquisição de informação na educação, apoiando a aprendizagem dos materiais didáticos e o desenvolvimento das habilidades particulares, através do uso de software educacional.

Dentre as ferramentas utilizadas como subsídio no processo de aprendizagem, encontra-se o $Q R$ code ou código $Q R$ (código de resposta rápida), o qual consiste em um gráfico 2D de uma caixa preto e branca bidimensional, podendo conter informações préestabelecidas na vertical e horizontal, como textos, páginas de internet, vídeos, entre tantas outras. Essa ferramenta é utilizada através de um aplicativo gratuito, escaneado por uma câmera de celular, como estratégia de auxílio à metodologia dos discentes, to rnando as práticas divertidas e atraentes (COPETTI; GHISLENI, 2012; GIARDELLI, 2016).

Dentre as escolas que utilizam as tecnologias de informação e comunicação (TICs) no auxílio à educação, está presente o colégio privado Losango, com sede na cidade de Ubá-MG.

A instituição utiliza o material pedagógico Bernoulli Sistema de Ensino, criado em 2000, o qual oferta materiais pedagógicos e ferramentas digitais tecnológicas como o código $Q R$, a fim de fornecer suporte completo para a escola, proporcionando uma formação de qualidade aos alunos.

Diante do exposto, sobre a utilização das tecnologias de informação e da comunicação no ensino fundamental, questiona-se: como o código $Q R$ pode contribuir para auxiliar na prática educacional?

Em linhas gerais, a pesquisa tem como objetivo analisar a utilização do código $Q R$ no Ensino Fundamental I das disciplinas básicas do Colégio Losango de Ubá-MG. Os objetivos específicos têm como propósito investigar o código $Q R$ no auxílio aos discentes e sua contribuição para o ensino aprendizagem nas aulas, identificar o papel do professor durante a utilização do código e pesquisar se existem dificuldades para os alunos em sua utilização. 


\section{Referencial teórico}

\section{1. $O$ universo das tecnologias e a educação}

Com a evolução e a facilidade de acesso aos recursos tecnológicos, culturas digitais como a maker, baseada no uso das tecnologias em sala de aula, foram criadas com a asserção de uma pedagogia que priorize o protagonismo do estudante, capaz de adquirir suas próprias ideias, ao invés de serem submetidos a padrões ideológicos. "O professor está lidando com uma geração mais crítica e participativa, tendo que buscar aproximar a sua realidade à dos alunos" (GEBRAN, 2009, p. 26).

De acordo com Prensky (2010), a tecnologia atual oferece aos alunos vários equipamentos eficazes para que possam ter autonomia do seu próprio conhecimento. Com a presença de ferramentas tecnológicas, acresce a capacidade de oferecer qualidade ao ensino, além de aproximar a escola do estudante que, por sua vez, tem o mundo digital integrado a sua realidade. "Quando um indivíduo se encontra em um ambiente estimulante, a camada exterior do seu cérebro se expande, e, com isso, a apreensão do aprendizado aumenta significantemente" (COSTA, 2014, p.17).

Os avanços das tecnologias de informação baseados na educação permitiram a criação de ferramentas conhecidas como softwares educacionais, que podem ser utilizadas como auxílio ao docente em sala de aula, a fim de ampliar as práticas educativas e potencializar a capacitação e aperfeiçoamento dos alunos. De acordo com Gebran (2009), a utilização dos variados tipos de softwares permite ao educando e ao educador crescerem ao mesmo tempo, ajustando-se a essa nova variante, procurando pela busca de informações.

Existem diversas opções de softwares educacionais utilizados para um melhor aproveitamento educacional e como uma nova forma de aprendizagem. O primeiro passo para conseguir se adaptar a esses novos desafios tecnológicos é conhecê-los. "Um dos grandes desafios para os educadores deste século é, com certeza, conseguir integrar os saberes e inserir novas tecnologias no ambiente interativo de aprendizagem" (COSTA, 2014, p.15).

Dentre os softwares educacionais, são exemplos o Kahoot, o Google Classroom e o código $Q R$. Como as opções são muitas, cabe ao professor buscar alternativas para adotá-las em sala de aula, de modo que despertem o interesse dos alunos e atendam a demanda da educação.

É notável que há mudanças e novos caminhos a se seguir na educação brasileira e esse contexto desafia as escolas e os professores a estarem abertos a saírem do método tradicional e vivenciar as práticas inovadoras em prol de uma melhor qualidade de ensino.

\subsection{A importância das TICs no processo de ensino aprendizagem}

A educação e a aquisição de conhecimento estão cada vez mais adentradas à informação e à comunicação. Com a revolução digital e a facilidade de acesso aos recursos tecnológicos, devido às contemporâneas Tecnologias de Informação e Comunicação (TICS) no sistema de ensino, abrem-se novas oportunidades à educação, atraindo com mais facilidade o interesse dos alunos. "Essa evolução das Tecnologias da Informação e da Comunicação (TICs) permite que a maioria da população tenha acesso à informação, o que traz mudanças profundas em várias áreas do saber, principalmente no campo acadêmico, onde são discutidos e construídos conhecimento" (LOBO; MAIA, 2015, p.17). 
Reis (2018) afirma que a educação está mudando, no entanto é preciso alterar os modelos tradicionais de ensino, com o auxílio da tecnologia, visando suprir as novas necessidades dos professores e alunos no âmbito escolar.

De acordo com Moran (2004), as tecnologias trazem correntes desafios pedagógicos para ambientes educacionais. Os docentes, em qualquer curso presencial, precisam aprender a coordenar variadas áreas e incorporá-las de forma aberta, branda e contemporânea.

Com o uso da tecnologia de Informação e comunicação, professores e alunos, através do trabalho colaborativo, podem comunicar-se, trocar experiências, adquirindo conhecimento que favorece o desenvolvimento pessoal e grupal, bem como a percepção de sua existência e desempenho na transformação da sociedade (ALMEIDA, 2004).

Para Silva (2018), cabe ao professor preparar o conteúdo de acordo com as individualidades e necessidades de cada aluno, utilizando as TICs como artifício, a fim de tornar as aulas mais dinâmicas.

O uso das TICs no âmbito escolar é uma forma de refinar a peculiaridade da ed ucação, pois oportuniza novos percursos para a aquisição do ensino e novas metodologias, com o objetivo de trazer benefícios para professores e alunos, aumentando o estímulo de ambos em sala de aula. "Por meio da TIC, induz à liberdade de expressar e comunicar sentimentos, registrar percepções, ideias, crenças e conceitos, refletir sobre o pensamento representado e reelaborá-Io" (ALMEIDA, 2001, p.7).

Portanto, é necessário que os ambientes educativos tirem proveito dos benefícios que a tecnologia é capaz de trazer, aprimorando novas formas de aprendizado.

\section{3. $O$ uso das tecnologias educacionais em materiais pedagógicos}

A tecnologia Educacional está tornando a aprendizagem dinâmica e interativa. Elas já estão presentes em parte das escolas brasileiras, desde os tradicionais laboratórios de informática, até o uso dos smartphones em sala de aula.

O congresso Nacional Decreta: Art. 10 Fica instituída a Política de Inovação Educação Conectada, em consonância com a estratégia 7.15 do Plano Nacional de Educação, aprovado pela Lei no 13.005, de 25 de junho de 2014, com o objetivo de apoiar a universalização do acesso à internet em alta velocidade e fomentar o uso pedagógico de tecnologias digitais na educação básica. (BRASIL, 2017, p.1).

O uso do material pedagógico associado às tecnologias educacionais é fundamental no andamento das aulas, pois é através dele que os professores fomentam a prática, possibilitando o entendimento das temáticas pelos alunos, além de tornar as aulas agradáveis e eficazes. "Trata-se de repensar a dinâmica do conhecimento no seu sentido mais amplo, e as novas funções do educador como mediador desse processo" (DOWBOR, 2011, p.13).

Torrezan (2009) acredita que a instituição escolar precisa estar motivada para atuar mutuamente com esse novo público e adotar práticas pedagógicas que acompanhem e encorajem esse novo perfil de aluno autônomo e criativo. Diante disso, as tecnologias digitais vêm sendo cada vez mais empregadas em materiais pedagógicos, com o propósito de contextualizar e promover diferentes meios de aprendizagens.

Através do uso de ferramentas tecnológicas, os estudantes podem aprender, com sabedoria e criatividade, a pesquisar e analisar as informações adquiridas com os 
aparelhos que trazem para aula. Assim, o ensino se tornará mais atraente a eles e proporcionará maior interatividade entre alunos e professores.

\subsection{O uso dos smartphones em sala de aula e o código QR como mediador des- se processo}

As tecnologias têm obtido cada vez mais espaço e motivado mudanças no cenário atual, com a transição do celular para o smartphone e as melhorias adicionadas a esse aparelho, o qual se considera ser a ferramenta mais influente na vida de todos.

De acordo com Costa (2014) e Silva et al. (2017), a utilização do smartphone como recurso pessoal tecnológico é um caminho que ampara a falta de infraestrutura tecnológica nas escolas, facilitando a organização de informações, estimulando o auto didatismo. É dever do professor, como agente de transformação e formador de opinião, disponibilizar aos alunos conhecimentos e interações com essas tecnologias.

Muitos estudantes possuem um smartphone, o qual pode ser utilizado como ferramenta para auxiliar no processo de ensino aprendizagem. Pesquisa realizada pelo Centro Nacional de Estudos para o Desenvolvimento da Sociedade da Informação CETIC (2018), e que faz parte da pesquisa Nacional TIC Educação de 2017, revela que se observou um crescimento no uso de smartphones entre crianças e adolescentes para o acesso à internet, chegando a 93\%, o que representa 23 milhões de jovens.

Em contrapartida, Ramos (2012) acredita que a presença constante do uso de celulares dentro da sala de aula que não seja introduzida como tecnologias de aprendizagem pode afetar o desempenho dos alunos, podendo haver distração e perda de foco.

Para Freitas e Carvalho (2017), diante da facilidade de execução de tarefas devido ao acesso às informações proporcionadas pelos smartphones, é preciso repensar a sala de aula como único espaço para aprender e ensinar, no sentido de o discente, conduzido por seu professor, poder acessar na internet as informações como auxílio para o que foi aprendido.

É primordial que os educadores se atualizem, tendo em vista a presença da tecnologia e o uso frequente do celular no cotidiano de inúmeras pessoas. Considerando esse fato percursor, sabe-se que a utilização dos meios de comunicação com respostas rápidas é uma necessidade do homem na atualidade. "A aplicação dos $Q R$ Codes no contexto educacional pode instigar a curiosidade dos sujeitos, provocando a ação e a interação, bem como uma nova forma de produzir e acessar a informação" (NICHELE et al., 2015, p.1).

O código $Q R$ (código de resposta rápida) é usado de inúmeras maneiras, encontradas em diversas áreas como lojas, estacionamentos, embalagens, cardápios, para um público mais conectado, por isso é a própria pessoa quem irá definir o que será inserido nesse código. Sua utilização é feita por um aplicativo, escaneado através de uma câmera de celular. $O$ uso dessa tecnologia é livre, portanto qualquer pessoa pode gerar um código desses.

De acordo com Vieira e Coutinho (2013), o uso do código $Q R$ poderá dar uma nova perspectiva às técnicas de ensino aprendizagem, inserindo uma nova prática, tornando o elemento novidade, como motivação extra para os alunos.

A utilização desse código dentro da sala de aula é mais simples do que parece e pode ser viabilizada em qualquer disciplina, construindo projetos, direcionando às crianças vídeos, dinâmicas, reportagens e até mesmo jogos educativos, a fim de conquistar o 
interesse dos alunos pelo que deve ser estudado, aumentando as chances de garantir o engajamento deles durante a apresentação da matéria.

2.5. O papel do professor frente às tecnologias dentro da sala de aula

A educação é o campo que oferece à população a estabilidade necessária para a obtenção de um mundo mais justo, e o professor é o profissional de intermédio nesse processo. Como qualquer outro método de ensino, saber aplicar na sala de aula faz toda diferença para um bom resultado final. Além disso, adotar os avanços tecnológicos dentro de sala de aula significa para o docente investir em si próprio, proporcionando ao outro o acesso à informação e sabedoria.

De acordo com Castro et al. (2008) e Mercado (2002), o papel do docente é estar engajado no processo consciente do uso das tecnologias, com o dever de habilitar as didáticas e também formar o estudante para que ele se torne operante na sociedade; ele deve planificar suas aulas de forma que o discente possa compreender a relevância do que está sendo aprendido, seja num contexto histórico, para seu cotidiano ou para seu futuro.

Por meio do computador ou celular, as tecnologias já fazem parte do cotidiano dos alunos e professores de qualquer instituição escolar. "O educador deve aproveitar as potencialidades do celular como recurso pedagógico, tendo em vista que é uma realidade presente na vida de todos educandos" (COSTA, 2014, p.93).

As tecnologias sozinhas não mudam a escola, e fazer com que esses recursos façam parte do processo de ensino e aprendizagem não é uma missão fácil. Na realidade, cabe ao docente ser o conciliador e incentivador no processo de ensino aprendizagem. $\mathrm{O}$ papel do professor diante dessas novas tecnologias é mais do que ensinar, é proporcionar aos discentes o acesso aos recursos tecnológicos.

Segundo Moran (2003), ensinare aprender, no momento presente, requer flexibilidade espaço-temporal, pessoal e de grupo, menos conteúdos fixos e uma metodologia baseada na pesquisa e comunicação. Ele ressalta que uma das grandes dificuldades atuais é conseguir conciliar o amplo acesso às informações que possuímos e a dificuldade em escolher quais são significativas para agregá-las em nossa vivência.

Os docentes precisam sentir-se entusiasmados pela prática de conhecer e aprender o manejo das tecnologias dentro do ambiente de ensino, de modo a possibilitar aos aprendizes entretenimento ao aprender o conteúdo. Cabe ao docente perceber a necessidade de en riquecer sua metodologia, esquecendo as aulas expositivas, nas quais o foco principal é o professor, abrindo espaço para dinâmicas e questionamentos. "Os nossos alunos só se tornam dispersos, rebeldes e desestimulados porque a aula de que ele participa não considera as mudanças no cenário atual global, desvinculando a realidade do seu espaço" (COSTA, 2014, p.17).

Contudo, primeiramente, é importante que o professor tenha conhecimento do tipo de tecnologia a ser utilizada, para que depois realize a preparação. Feito isso, o docente deve utilizar a técnica e novos recursos que se estabelecem por meio dessa metodologia, constituindo um ambiente intermédio, acessível e respectivo, sempre que possível, por meio de indagações e orientações. 


\section{Metodologia}

Para realizar este estudo de caso descritivo, de cunho pedagógico e teórico acerca da construção de conhecimento, realizou-se uma pesquisa de campo de natureza quali-quantitativa.

Gunther (2006) destaca que a utilização da junção da pesquisa qualitativa e quantitativa permite mais informações do que se poderia conseguir separadamente, obtendo-se uma análise mais profunda do assunto tratado na pesquisa.

De acordo com Dalfovo et al. (2008), a pesquisa qualitativa trabalha com informações, comportamentos e compreensões coletadas pelo pesquisador, relacionada no levantamento de dados de uma população.

Manzato (2012) afirma que a pesquisa quantitativa é realizada por meio dos números, quando se quer medir opiniões, comportamentos, hábitos e reações de um público alvo, de forma estatisticamente comprovada.

Pereira et al. (2018, p. 266) asseguram que "um estudo de caso é uma descrição e análise, a mais detalhada possível, de algum caso que apresente alguma particularidade que o torna especial".

Gil (1999) afirma que a pesquisa descritiva tem como principal objetivo descrever características de determinada população ou fenômeno ou definição entre determinados elementos.

Spink (2003) reconhece que a pesquisa de campo é empregada na extração de dados e informações obtidas "em campo", onde os acontecimentos ocorrem de forma natural.

É também um trabalho bibliográfico, "porque busca informações e dados disponíveis em publicações - livros, teses e artigos de origem nacional ou internacional, e na internet, realizados por outros pesquisadores" (RODRIGUES, 2007, p. 29).

\subsection{Local da pesquisa e instrumento para coleta de dados}

O estudo ocorreu no colégio privado Losango, com sede na cidade de Ubá-MG. Os sujeitos das pesquisas constituíram-se na coordenadora/docente e nos discentes que atuam e estudam, respectivamente, no Ensino Fundamental I.

Como instrumento para a coleta das informações para a pesquisa, na primeira parte, foi realizada uma entrevista com a coordenadora/docente do Ensino Fundamental I, composta por onze questões norteadoras, seguindo roteiro semiestruturado, que aconteceu em um local disponível na escola.

Segundo Júnior e Júnior (2012), a entrevista é uma das metodologias mais empregadas atualmente em trabalhos científicos, pois proporciona ao pesquisador extrair uma abundância de dados e informações que possibilite um trabalho satisfatório.

Na segunda parte, foi aplicado um questionário aos alunos, contendo dez questões fechadas, o qual foi distribuído aleatoriamente para os anos do Ensino Fundamental I da escola em estudo, a fim de verificar como eles percebem e vivenciam o processo da apropriação do código $Q R$ dentro dos materiais pedagógicos. Esse questionário foi confeccionado de forma simplificada, usando a maior parte das perguntas no proces so dicotômico de sim ou não, em virtude da idade dos entrevistados.

Deste modo, através da aplicação de um questionário a um públicoalvo constituído, por exemplo, de alunos, é possível recolher informações que permitam conhecer melhor as suas lacunas, bem como me- 
Ihorar as metodologias de ensino podendo, deste modo, individualizar o ensino quando necessário. (AMARO et al., 2005 p. 3).

Para a coleta de dados, foi encaminhada à instituição uma carta de apresentação contendo os objetivos e propósitos do estudo. A coleta aconteceu nos dias e horários de preferência da coordenadora/docente entrevistada. Só fizeram parte da amostra final aqueles que responderem completamente ao questionário.

A interpretação dos dados coletados qualitativos foi inserida no software gratuito Iramuteq, o qual possibilita uma análise estatística legítima sobre os dados presentes.

Este programa informático viabiliza diferentes tipos de análise de dados textuais, desde aquelas bem simples, como a lexicografia básica (cálculo de frequência de palavras), até análises multivariadas (classificação hierárquica descendente, análises de similitude). Ele organiza a distribuição do vocabulário de forma facilmente compreensível e visualmente clara (análise de similitude e nuvem de palavras). (CAMARGO; JUSTO, 2013, p. 515).

Por meio desse software, a distribuição do vocabulário pode ser organizada de forma facilmente coerente e visualmente perceptível, com representações gráficas pautadas nas análises lexicográficas.

Referentemente aos dados quantitativos, foi utilizado o Excel Office 365, aplicativo de editor de planilhas oferecido no pacote da Microsoft, capaz de auxiliar no ensino aprendizagem da estatística (ARAYA, 2007).

\section{Resultados e discussão}

\subsection{Universo da pesquisa}

Os dados foram coletados, na primeira parte, por uma entrevista com a coordenadora/docente do Ensino Fundamental I do colégio privado Losango de Ubá-MG, composta por onze questões norteadoras, seguindo roteiro semiestruturado, em um local disponível na escola.

Na segunda parte, totalizando 129 estudantes das séries sortidas do Ensino Fundamental I do colégio Losango de Ubá-MG, foram aplicados questionários, dos quais somente 15 alunos entre 6 e 9 anos e 15 alunos entre 10 e 13 anos fizeram parte da amostra final, ao responderem completamente às questões.

\subsection{Resultado da entrevista}

Para análise da entrevista, foi utilizado o software Iramuteq para gerar a nuvem de palavras, a qual, com o intuito de trazer uma imagem representativa, abarca somente palavras ativas em negrito, para melhor visualização e clareza no que se refere à compreensão do estudo. Conforme Camargo e Justo (2013, p. 6), "a nuvem agrupa as palavras e as organiza graficamente em função da sua frequência. É uma análise lexical mais simples, porém graficamente interessante".

Dentro desse software, foi constituído o corpus geral (objeto de análise) por um texto de entrevista, do qual emergiram 330 ocorrências (palavras, formas ou vocábulos), sendo 80 palavras distintas e 250 com uma única ocorrência. As palavras que se encontram em negrito no texto, referem-se às que aparecem com maior frequência no decorrer da entrevista. 
Figura 1: Nuvem de palavras da entrevista

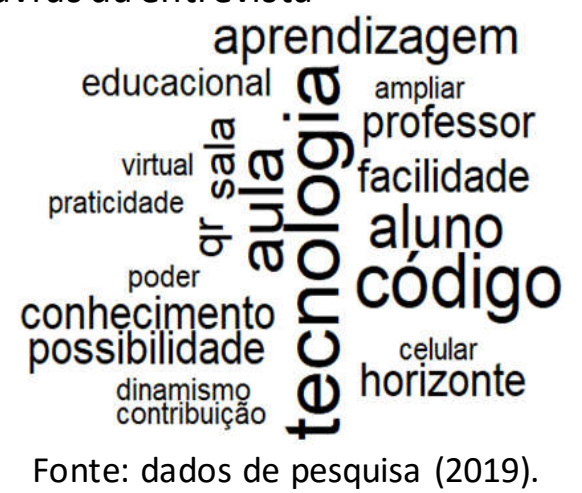

A entrevistada é coordenadora e atua também como professora do Ensino Fundamental I do Colégio Losango de Ubá-MG. Ela afirma que o código qr pode contribuir para auxiliar na prática educacional ao permitir atravessar as paredes da escola, ampliar os horizontes dos alunos, assegurando que acessem infinitas possibilidades de aprendizagem, que vão de exercícios a vídeos e jogos educativos; o qual traz consigo a tecnologia educacional para o universo da sala de aula, fazendo com que o aluno se sinta integrado ao ambiente que gosta o - virtual -, e paralelamente estar construindo conhecimentos.

De acordo com Prensky (2010), a tecnologia atual oferece aos alunos vários equipamentos eficazes para que possam ter autonomia do seu próprio conhecimento. Com a presença de ferramentas tecnológicas, acresce a capacidade de oferecer qualidade ao ensino, além de aproximar a escola do estudante, o qual, por sua vez, tem o mundo digital integrado a sua realidade.

A entrevistada evidencia a facilidade dos professores e alunos no manuseio e utilização dessa ferramenta, a qual trouxe mais modernidade e dinamismo para dentro da sala de aula. Contudo, certifica que nunca houve erro na leitura do código.

Ramos (2012) acredita que a presença constante do uso de celulares dentro da sala de aula que não seja introduzida como tecnologias de aprendizagem pode afetar o desempenho dos alunos, podendo haver distração e perda de foco.

De acordo com a entrevistada, é importante salientar que nem todos os alunos possuem um celular. Quando isso ocorre, a professora faz a leitura do código qr em sua classe com o próprio aparelho e demonstra para o aluno sua função; ou o aluno pode baixar o aplicativo que faz a leitura do código em seu tablet, ipad ou no smartphone dos pais em casa. No entanto, o uso do celular é proibido durante as aulas, sendo utilizado somente como metodologia direcionada, não havendo questões como distração ou perda de foco.

De acordo com Castro et al. (2008) e Mercado (2002), o papel do docente é estar engajado no processo consciente do uso das tecnologias, com o dever de habilitar as didáticas e também formar o estudante para que ele se torne operante na sociedade; ele deve planificar suas aulas de forma que o discente possa compreender a relevância do que está sendo aprendido, seja num contexto histórico, para seu cotidiano ou para seu futuro.

Todavia, é relevante compreendermos que o código qr é utilizado como complementação da explicação do professor - o qual assume a postura de facilitador pedagógico - ou é empregado também como atividade a ser realizada como tarefa escolar. 
Ao final da entrevista, a coordenadora deixou uma mensagem acerca da visão de docente sobre a inserção das tecnologias dentro da sala de aula: "As tecnologias, quando bem empregadas, só têm a contribuir com o processo ensino-aprendizagem. Elas não podem nem devem ser usadas somente por modismo ou como uma obrigação para modernizar as aulas. Por isso, seu uso exige pesquisa e entendimento, para que sejam realmente bem aproveitadas na construção do conhecimento".

\subsection{Resultado dos questionários}

Fizeram parte da amostra final trinta participantes, sendo quinze alunos entre 6 e 9 anos e quinze alunos entre 10 e 13 anos, das séries sortidas do ensino fundamental I do Colégio Losango de Ubá-MG, a fim de realizar um comparativo entre os discentes de idade menor e maior, mediante aos dados coletados.

É essencial salientar que $100 \%$ dos alunos de ambas as faixas etárias alegaram gostar, sentir-se confortáveis e não possuir nenhuma dificuldade ao utilizar o código $Q R$ dentro de sala de aula.

"O aparelho celular se apresenta como uma ferramenta disponível e que pode prontamente ser incorporada como objeto de aprendizagem" (DA FONSECA, 2013, p.170).

Através da Figura 2, pode-se perceber que 53,33\% alunos entre 6 a 9 anos possuem um smartphone e $46,66 \%$ não o possui. Já os alunos de 10 a 13 anos $86,66 \%$ possuem um smartphone e 13,33 \% não possuem. Podemos concluir que a média maior dos alunos que possuem smartphone se refere aos de idade maior, entre 10 a 13 anos.

Figura 2: Você possui um smartphone?

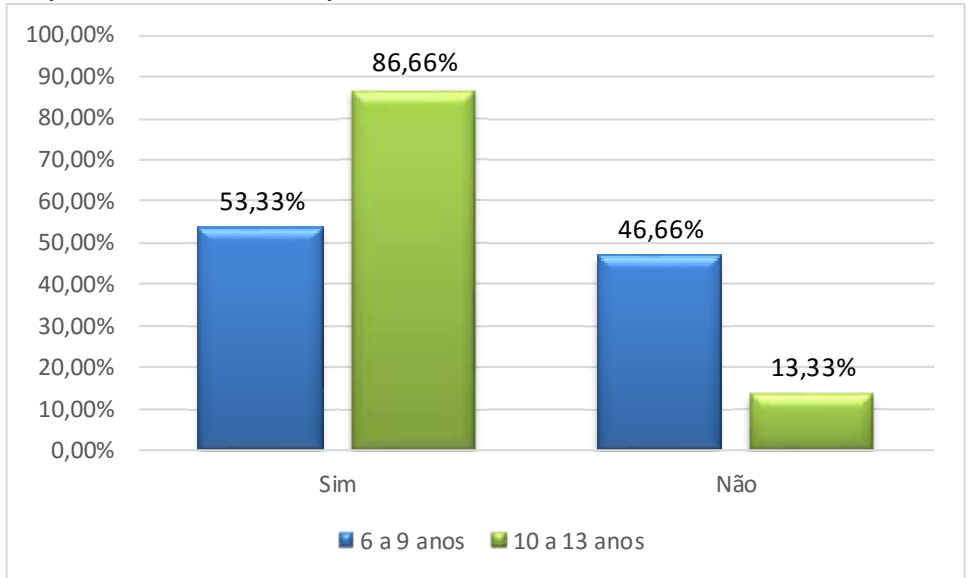

Fonte: dados da pesquisa (2019).

Brandão e Vargas (2016, p. 9) afirmam que "o uso de tecnologias e dispositivos digitais para ampliar o acesso à educação de qualidade é um fenômeno em franca expansão e convida a uma profunda reflexão sobre o futuro dos processos de ensino e aprendizagem".

Através da Figura 3, pode-se perceber que ao questionar com que frequência utilizam o código $Q$ r, 60\% dos alunos entre 6 a 9 anos afirmam utilizar poucas vezes, enquanto 53,33\% dos alunos entre 10 a 13 anos afirmam que quase nunca utilizam o código dentro de sala de aula. 
Figura 3: Com que frequência utiliza o código $Q R$ em sala de aula?

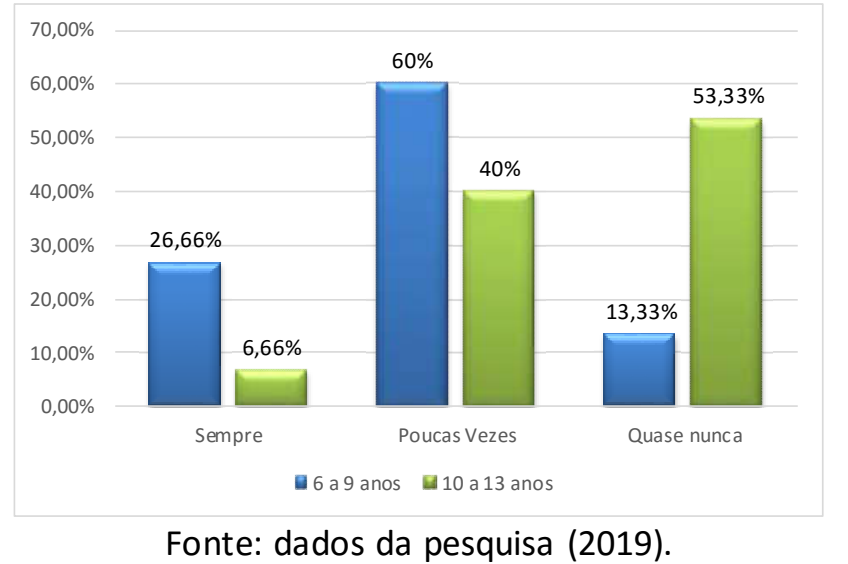

Segundo Moran (2003), ensinar e aprender, no momento presente, requer flexibilidade espaço-temporal, pessoal e de grupo, menos conteúdos fixos e uma metodologia baseada na pesquisa e comunicação.

A Figura 4 evidencia uma diferença significativa nos dados, nos quais somente 20\% dos alunos entre 6 a 9 anos havia utilizado seu smartphone em alguma prática em sala de aula, enquanto 53,33\% dos alunos entre 10 a 13 anos já o havia feito.

Figura 4: Antes da utilização do código $Q R$ em seu material pedagógico, você havia utilizado seu smartphone em alguma prática em sala de aula?

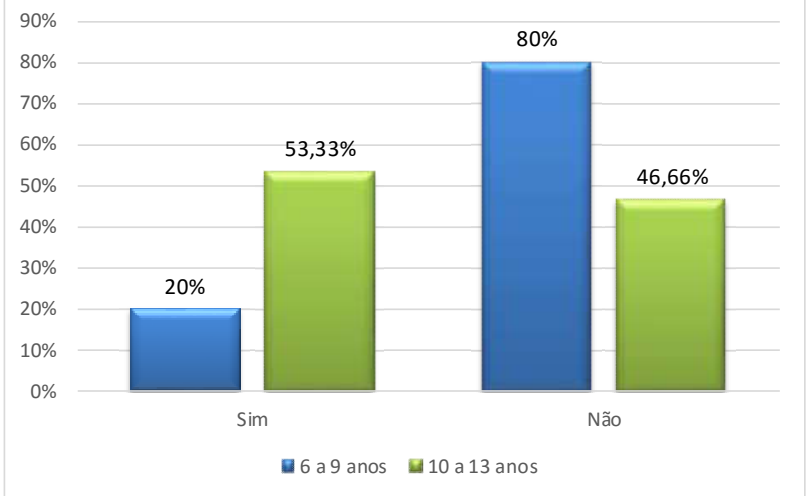

Fonte: dados de pesquisa (2019).

\section{Considerações finais}

A pesquisa foi realizada com o objetivo de analisar a utilização do código $Q R$ no Ensino Fundamental I das disciplinas básicas do Colégio Losango de Ubá-MG. Durante a realização da pesquisa, foi assumido o papel do docente como mediador na junção da educação e tecnologia em um processo de ensino aprendizagem.

Diante dos resultados obtidos na escola, no que concerne à aplicação do código $Q R$ nas atividades dentro de sala de aula, a coordenadora/docente confirmou a facilidade em sua utilização, reconhecendo que, em nenhum momento, houve erro na leitura do código. Ela evidenciou também a contribuição dessa ferramenta na prática educacional, ao proporcionar aos alunos infinitas possibilidades de aprendizagem, que vão de exercícios a vídeos e jogos educativos, fazendo com que o aluno se sinta integrado ao ambiente de que gosta - o virtual - e paralelamente construa conhecimentos. Ela enfatiza o fato de o uso do smartphone ser proibido durante as aulas, sendo utilizado somente como metodologia direcionada, evitando questões como distração ou perda de foco. 
Através da aplicação do questionário aos alunos, infere-se que, apesar de nem todos os estudantes possuírem um smartphone, $100 \%$ deles se sentem confortáveis e não manifestam qualquer dificuldade ao utilizar o código durante as atividades educativas.

O desenvolvimento do tema permitiu articular conhecimentos adquiridos ao longo do curso com a prática do ambiente escolar, em busca dos objetivos do fazer acont ecer. Com isso, pode-se perceber a necessidade de projetos pedagógicos que considerem o smartphone como ferramenta de pesquisa, visto que, para a obtenção de resultados significativos na educação, é de extrema importância que os educadores recebam in struções de como utilizar esse recurso.

Os resultados obtidos neste artigo vão ao encontro dos objetivos traçados no início da pesquisa, a qual aponta o código $Q R$ como um facilitador pedagógico no transcurso do processo de ensino-aprendizagem, ao longo do Ensino Fundamental I.

Nesse sentido, dada a importância do assunto, conclui-se que o código $Q R$ nos materiais didáticos funciona como ferramenta que auxilia com benefício na transmissão de conhecimentos, além de assegurar incontáveis possibilidades de aprendizagem, trazendo a tecnologia educacional para o universo da sala de aula.

Não é pretensão deste trabalho findar o tema abordado, portanto fica aqui a possibilidade de novos pesquisadores discutirem o assunto em novos trabalhos, o que certamente engrandecerá o tema tratado na pesquisa.

\section{Referências}

ALMEIDA, Maria Elizabeth Bianconcini. Tecnologia de informação e comunicação na escola: aprendizagem e produção da escrita. Série "Tecnologia e Currículo" - Programa Salto para o Futuro, nov. 2001.

ALMEIDA, Maria Elizabeth Bianconcini. Tecnologia de informação e comunicação na escola: novos horizontes na produção escrita. Ensaio. Avaliação e Políticas Públicas em Educação, Rio de Janeiro, v. 12, n. 43, p. 711-725, 2004.

AMARO, Ana; PÓVOA, Andreia; MACEDO, Lúcia. A arte de fazer questionários. Porto, Portugal: Faculdade de Ciências da Universidade do Porto, 2005.

ARAYA, Ronny Gamboa. Uso de la tecnología en la enseñanza de las matemáticas. Cadernos de Investigación Matemática, 2007.

BRANDÃO, Daniel; VARGAS, Ana Carolina. Avaliação do uso de tecnologias digitais na educação. Experiências avaliativas de tecnologias digitais na Educação, p. 9, 2016.

BRASIL. Política de Inovação Educação Conectada. Decreto nํ 13.005, de 25 de junho de 2014. Disponível em: https://www.camara.leg.br/proposicoesWeb/prop_mostrarintegra;jsessionid=5BF9020E724353AB392578D972B44E54. proposicoesWebExterno2?codte or=1630000\&filename=Avulso+-PL+9165/2017. Acesso em: 15 mar. 2019.

BRITTO JÚNIOR, Álvaro Francisco de Britto; FERES JÚNIOR, Nazir Feres. A utilização da técnica da entrevista em trabalhos científicos. Revista Evidência, v. 7, n. 7, 2012.

CAMARGO, Brigido Vizeu; JUSTO, Ana Maria. IRAMUTEQ: um software gratuito para análise de dados textuais. Temas em Psicologia, v. 21, n. 2, p. 513-518, 2013. 
CASTRO, Patrícia Aparecida Pereira Penkal; TUCUNDUVA, Cristiane Costa; ARNS, Elaine Mandelli. A importância do planejamento das aulas para organização do trabalho do professor em sua prática docente. ATHENA Revista Científica de Educação, v. 10, n. 10, 2008.

COPETTI, Cinara; GHISLENI, Taís Steffenello. Mobile marketing: a tecnologia qr code utilizada em ação da Heineken. Disciplinarum Scientia| Sociais Aplicadas, v. 8, n. 1, p. 59-69, 2012.

COSTA, Ivanilson. Novas tecnologias e aprendizagem. 2. ed. Rio de Janeiro: Wak Editora, 2014.

FONSECA, Ana Graciela Mendes Fernandes. Aprendizagem, mobilidade e convergência: mobile learning com celulares e smartphones. Revista Mídia e Cotidiano, v. 2, n. 2, p. 265-283, 2013.

DALFOVO, Michael Samir; LANA, Rogério Adilson; SILVEIRA, Amélia. Métodos quantitativos e qualitativos: um resgate teórico. Revista Interdisciplinar Científica Aplicada, v. 2, n. 3, p. 1-13, 2008.

DOWBOR; Ladislau Tecnologias do conhecimento: os desafios da educação. 5. ed. Petrópolis, RJ: Vozes, 2011.

FIORIO, Rosaine; ESPERANDIM, Rauany; SILVA, Flávio; VARELA, Paulo; LEITE, Maici; REINALDO, Francisco. Uma experiência prática da inserção da robótica e seus benefícios como ferramenta educativa em escolas públicas. In: Brazilian Symposium on Computers in Education (Simpósio Brasileiro de Informática na Educação-SBIE), 2014, p. 1223.

FONSECA, Ana Graciela Mendes Fernandes da. Aprendizagem, mobilidade e convergência: mobile learning com celulares e smartphones. Revista Mídia e Cotidiano, v. 2, n. 2, p. 265-283, 2013.

FREITAS, Raphael; CARVALHO, Mercedes. Tecnologias móveis: tablets e smartphones no ensino da matemática. Laplage em Revista, v. 3, n. 2, p. 47-61, 2017.

GEBRAN, Maurício Pessoa. Tecnologias educacionais. Curitiba: IESDE Brasil SA, 2009.

GIARDELLI, Gil. Você é o que você compartilha: e-agora: como aproveitar as oportunidades de vida e trabalho na sociedade em rede. Editora Gente, 2016.

GIL, Antônio Carlos. Métodos e técnicas de pesquisa social. 5. ed. São Paulo: Atlas, 1999.

GÜNTHER, Hartmut. Pesquisa qualitativa versus pesquisa quantitativa: esta é a que stão. Psicologia: teoria e pesquisa, v. 22, n. 2, p. 201-210, 2006.

LOBO, Alex Sander Miranda; MAIA, Luiz Cláudio Gomes. O uso das TICs como ferramenta de ensino-aprendizagem no Ensino Superior/Use of technologies of information and knowledge as teaching-learning tools in higher education. Caderno de Geografia, v. 25, n. 44, p. 16-26, 2015.

MANZATO, Antonio José; SANTOS, Adriana Barbosa. A elaboração de questionários na pesquisa quantitativa. Departamento de Ciência de Computação e Estatística - Universidade de Santa Catarina, 2012.

MERCADO, Luís Paulo Leopoldo. Novas tecnologias na educação: reflexões sobre a prática. Maceió: EDUFAL, 2002. 
MORAN, José Manuel. Mudar a forma de ensinar e de aprender com tecnologias: transformar as aulas em pesquisa e comunicação presencial-virtual. In: MORAN, J. M.; MASETTO, M.; BEHRENS, M. Novas tecnologiase mediação pedagógica. Campinas: Papirus, 2003, p. 11-65.

MORAN, José Manuel. Os novos espaços de atuação do professor com as tecnologias. Revista Diálogo Educacional, v. 4, n. 12, 2004.

NICHELE, Aline Grunewald; SCHLEMMER, Eliane; FARIAS RAMOS, Adriana de. QR codes na educação em química. RENOTE, v. 13, n. 2, 2015.

PEREIRA, Adriana Soares; SHITSUKA, Dorlivete Moreira; PEREIRA, Fábio José; SHITSUKA, Ricardo. Metodologia da pesquisa científica. Santa Maria: UAB / NTE / UFSM, 2018.

PONTE, João Pedro da. As TIC no início da escolaridade: perspectivas para a formação inicial de professores. A formação para a integração das TIC na educação pré-escolar e no 1. o ciclo do ensino básico, p. 19-26, 2002.

PORTAL CETIC.br. Cetic.br pesquisa o uso de celular por alunos para a realização de at ividades escolares. Disponível em: https://www.cetic.br/noticia/cresce-numero-decriancas-e-adolescentes-que-buscam-noticias-na-internet-aponta-cetic-br/. Acesso em: 26 mar. 2019.

PRENSKY, Marc. O papel da tecnologia no ensino e na sala de aula. CONJECTURA: filos ofia e educação, v. 15, n. 2, 2010.

RAMOS, Márcio Roberto Vieira. O uso de tecnologias em sala de aula. Revista Ensino de Sociologia, v.1, p.1, 2012.

REIS, Fábio. Inovar para transformar: como a inovação pode mudar o ensino superior. São Paulo: Cultura, 2018.

RODRIGUES, William Costa. Metodologia científica: conceitos e definições. FAETEC/IST Paracambi, 2007.

SILVA, Denis; RODRIGUES Raquel; FLIPPERT, Vania; BOSCARIOLI, Clodis. Out. 2017. Usando Smartphones, QR Code e Games of Thrones para gamificar o ensino e aprendizagem de termometria. In: Anais do Workshop de Informática na Escola, v. 23, n. 1, p. 658.

SILVA, Maria de Jesus de Sousa. Tecnologia na educação: as TICs e a formação do professor de língua portuguesa no ensino fundamental. Dissertação (Mestrado) - Universidade Federal do Maranhão, 2018.

SPINK, Peter Kevin. Pesquisa de campo em psicologia social: uma perspectiva pósconstrucionista. Psicologia \& Sociedade, v. 15, n. 2, p. 18-42, 2003.

TORREZZAN, Cristina Alba Wildt. Design pedagógico: um olhar na construção de materiais educacionais digitais. Dissertação (Mestrado) - Universidade Federal do Rio Grande do Sul, 2009.

VIEIRA, Liliana de Sousa; COUTINHO, Clara Pereira. Mobile learning: perspectivando o potencial dos códigos QR na educação. In: VII Conferência Internacional de TIC na Educação, Challenges 2013. Universidade do Minho. Centro de Competência do Projecto Nónio Século XXI, 2013. p. 73-91. 